\title{
Review of Stoichiometric Technique for Better Performance of the Boiler
}

\author{
Prosper Ndizihiwe ${ }^{1}$, Dr. Burnet Mkandawire ${ }^{2}$, Dr. Venant Kayibanda ${ }^{3}$ \\ ${ }^{1}$ University of Rwanda, College of Sciences and Technology, Rwanda \\ ${ }^{2}$ University of Malawi, Faculty of Engineering, Malawi \\ ${ }^{3}$ University of Rwanda, College of Sciences and Technology, Rwanda
}

\begin{abstract}
The combustion within the boiler burns fuel to create heat energy which then produces electrical power. The combustion of fuel is its reaction with oxygen available in the air. The amount of fuel that can be well burnt is limited by the quantity of oxygen. Once all the fuel is not burnt at all, some of it stays in the boiler and other quantity goes to the atmosphere. Most of the fuels used in the boiler are hydrocarbons which release hydrogen and carbon as residuals. It causes small efficiency and deg radation of the air. It is needed to take the faction of air/fuel to the optimum value to reduce these problems. This paper provides different reviewed algorithms that control the combustion within the boiler and the role of environmental temperature. The author found that the separation of the oxygen from the air combined with the preheating both fuel and oxygen taking into account environmental temperature would provide better stoichiometric values, which improve the performance.
\end{abstract}

Keywords: Boiler, Combustion, Air fuel ratio, Fuel, Oxygen Control.

\section{INTRODUCTION}

Energy is indispensable for the development of people. One way to generate energy is the combustion of fossil fuel within the boiler, which also take a big percentage[1],[2]. Most of the fuels used in the boiler are hydrocarbons, its combustion process is also referred to as the oxidation equation since it requires having oxygen; however, the hydrocarbon is combined with other elements in the air [3]. General combustion equation of hydrocarbon is given by

$$
C_{a} H_{b}+(a+b) \mathrm{O}_{2} \stackrel{\text { gives }}{\longrightarrow}(b / 2) \mathrm{H}_{2} \mathrm{O}+a \mathrm{CO}_{2}
$$

$C$ is Carbon, $H$ is Hydrogen, $O$ is Oxygen, $a$ and $b$ are constants[4].

This equation shows the complete combustion. In reality, this is not what happens because oxygen is found as air combined with other elements $21 \%$ of oxygen and $78 \%$ of nitrogen [5]. So the equation becomes

$$
C_{a} H_{b}+(a+b)\left(O_{2}+3.78 N_{2}\right) \stackrel{\text { gives }}{\longrightarrow}(b / 2) H_{2} 0+a C O_{2}+3.78(a+b / 4) N_{2}
$$

[4]. This means for every mole of fuel to be burned require $a+b$ moles of Oxygen and 3.76 $(a+b)$ moles of Nitrogen, and $3.76(a+b / 4)$ moles of Nitrite is generated [4], [6].

The stoichiometric or air-fuel ratio (AFR) is the fraction of the air to fuel in the combustion process within the boiler and others for the thermal power plant to burn the fuel to produce heat energy which then transformed into kinetic energy [7]. In the case this ratio is small (when the air is insufficient), it results in incomplete combustion which is the cause of low efficiency and much exhaust gases.[8] In the cases of bigger ratio (too much air presence), there will be the formation of much nitrogen $\left(N_{2}\right)$ as indicated by Figure 1 and its composition such as nitrite oxide $N O_{x}$ as indicated by Figure 4 [9], which are losses and at the same time are accumulated within the burner then disable the next process while reducing the lifetime of the boiler [10]. 
Different researches have been conducted to control this AFR however there is still a lack of the best way to achieve the exact value of AFR to have optimum combustion considering fuel properties, outdoor temperature, impurities attached to hydrocarbon.

This paper reviews the research done so far for various types of fuel. Some determine the novelty of increasing and decreasing the burning air, others explore the role of oxygen and impurities separation, while some of them investigate the impacts of the external climate. Some control algorithms have also been reviewed and discussed. Reviewing the literature gives the capability of comparison in view to choose what can be adapted for the project planned considering the specific situation. The authors also look at the gap of each method and then find the additional thing to do for better results. This paper reviews different models and control parameters in Section 2. In section 3 the impact of climate characteristics is reviewed, and the last section draws the summary and conclusion.

\section{MODELING AND CONTROL OF PARAMETERS INVOLVED IN THE COMBUSTION PROCESS}

To understand well the thermodynamics of gasification operation of biomass to harvest more clean combustibles for electrical generation, etc. Samson and Shaharin in [11] studied the performance of the downdraft biomass gasifier (DBG) utilizing Oil Palm Fronds (OPF) with ASPEN PLUS process simulator software for modeling and simulation of the different stages of the gasification procedure. The results have shown that the fraction of mass of the fuel elements $\mathrm{CO}$ and $\mathrm{CH}_{4}$ becomes higher at for a small air-fuel ratio. The mass fraction of $\mathrm{CO}_{2}$ increment is shown as the air-fuel ratio increases to Figure 1. This clarifies the necessity of controlling the air-fuel ratio to reduce negative emissions. The simulation also shown that the fraction of fuel varies with temperature and pressure, it emphasizes the need to know the optimum working condition in terms of temperature and pressure in biomass gasification. Experimental done on OPF, found the role of working on other sources on biomass to estimate the value of the AFR that minimizes all gases that were rooted in losses.

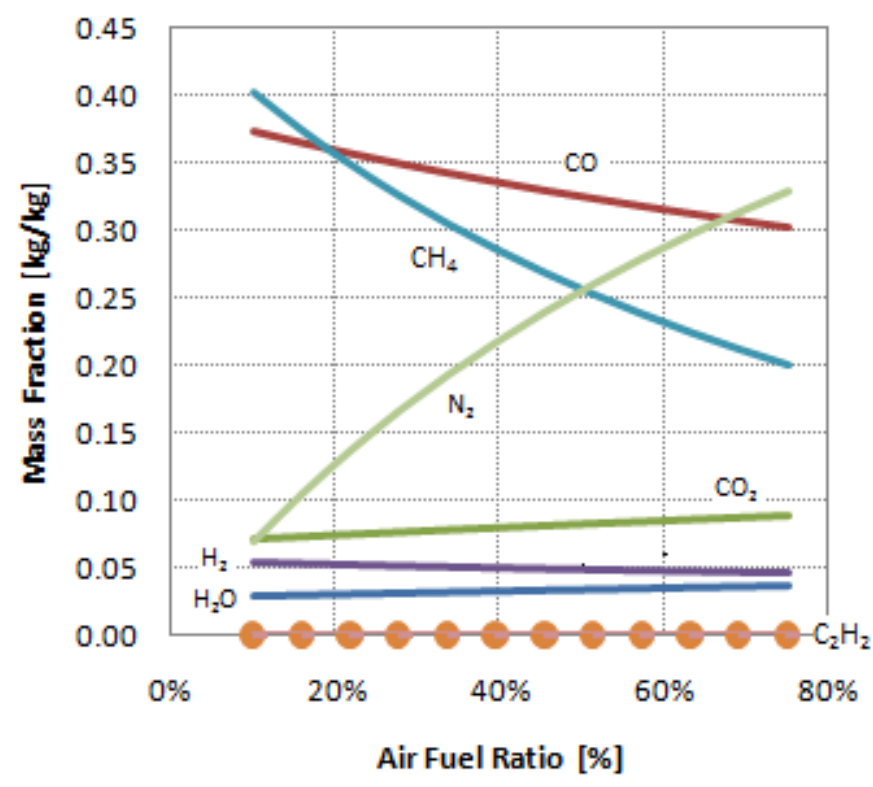

Figure 1: Variation of the mass fraction with AFR [11]

Liang et al [12] studied the method to design control algorithms; including architectural systems configuration. They proposed to design for optimizing air to fuel ratio and implementation of the control block. The background of the work is the fault of control effects, breakdown, and unavailability of test information from fields, and high cost caused by manual control, semi-automatic control, analog communication, and point-to-point topology data transmission. Liang found that the difference in air pressure for pre-heater inlet and outlet can be employed as an airflow measure by using Differential Pressure Detecting; the heat released from the boiler can be the measure to represent actual fuel. The method has been tested and run; they found that it gives stable output, with optimal combustion rate and reduced emission considerably, so they recommend the method. The research didn't investigate the requirement of the AFR specifically for a given fuel and didn't consider influencing parameters like the entrance temperature of both the air and the fuel.

Monitoring gas composition in the combustion chamber is very important in view to maximize efficiency and reduce losses. This fact stimulated Lizica et al [6] to develop the web application for combustion calculation. It calculates the chemical composition 
of solid fuels and air required. The author recommends the use of this application in the designing stage of the combustion. Their computations are based on the approximate composition of oxygen (21\%) and nitrogen (79\%). The research is limited to the computation of requirements didn't consider some other factors that can influence the combustion.

Santoso et al [13] conducted the research to control the use of the air to fuel ratio optimization, for combustion procedure within the boiler. The background of their research is the fact that the nonlinear and complex combustion system of a boiler needs a suitable controller that responds faster which was not achieved by the classical PI controller. Better functioning of the combustion was realized using a Fuzzy Logic Controller (FLC) against a conventional PI Controller see Figure 2, comparison diagram. The results show the reduction of air excess and increase combustion efficiency for fuzzy logic better than PI control. The research is limited to control of the flow of the air utilizing measuring the error between actual AFR and setting the referred AFR but did not describe what to be considered to set the value. The researcher recommends the use of FLC since it responds quickly and in terms of economy, it has more savings that PI method.
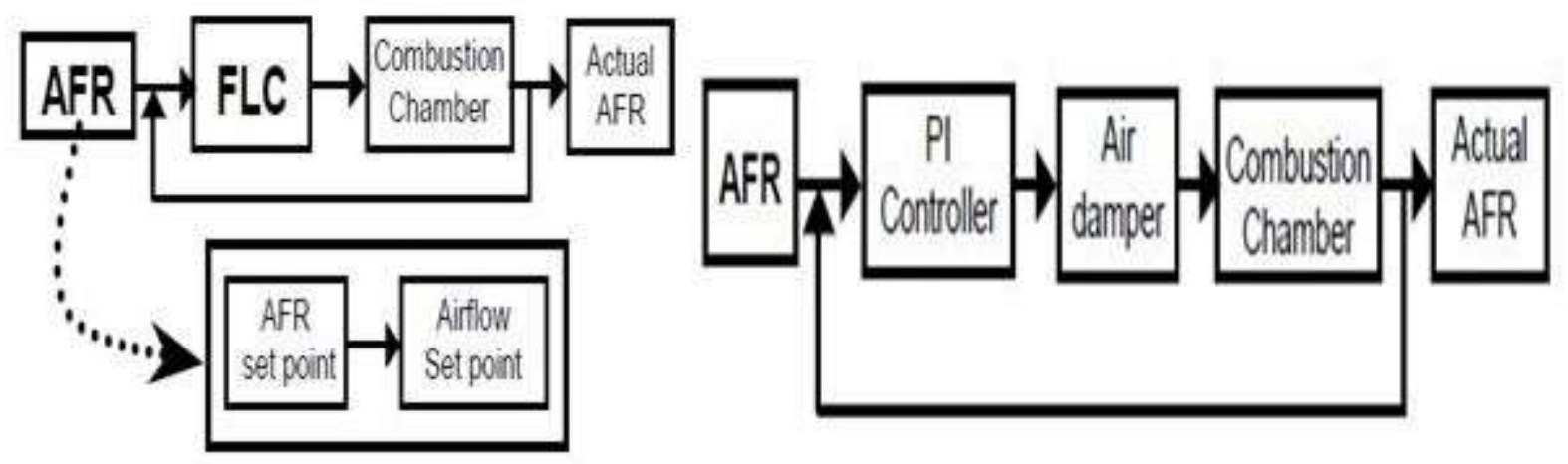

Figure 2: Fuzzy Logic Control (left) and Proportional Integral Control (right).

Blondeau et al [14] proposed the online monitoring system of the air-fuel combining two techniques: microwave probe for fuel composition and smart soft sensors for air to quantify the fuel and airflow. The combination of the two allows the computation of local air-fuel ratios. The background of the work is that local measurements are not re-calibrated according to the lifetime of the boiler which causes less reliability and these airflow measurements are not at each burner; they suppose that the fuel distribution between burners of the boiler is the same. The proposed methodology was proved helpful in assessing locally the air-fuel ratios for large pulverized-fuel boilers after being tested on the boiler of a $660 \mathrm{MWe}$ coal-fired Pulverized-Fuel (PF)-boiler. The research arrived at the reliable measurement methodology but was limited to the calculation and measurement of the AFR; it didn't quantify the mass of oxygen as the only needed composition of the air to achieve better combustion and didn't take into account the specific AFR for any type of the fuel.

Oversizing the boiler, and outdated system of operation of the pre-existing operation of the boiler system increases the system energy consumption and leads to much higher emission of carbon dioxide $\left(\mathrm{CO}_{2}\right)$. Some boilers with multiple burners don't make good use. In that end, Bei Zhang et al [15], investigated a single burner mode with air/fuel ratio adjustment to the optimum level. Because most of the time sites boilers work under partial load according to the demand, it can have two burners that can operate separately. Therefore, single and double burner mode were proposed and tested. In the work, they calculated the excess air percentage by the Ashrae equation found in [16]. The implementation of a single burner instead of multiple burners enables to adapt the change, improved the efficiency by $7 \%$ under low load condition. The authors recommend that for a double burner boiler all burners should have the same firing rate. Indeed, they advise the installation of Variable Frequency Drive (VFD) at all Force Draft (FD) fan since it saves power at around $80 \%$ apart from its main role of controlling the air flow rate and feed water. The researcher didn't explore the role of the inlet temperature of both air and fuel.

Ibrahim and Farrukh [17] studied the air to air with premixing the fuel and the air before there introduced to the furnace. The background of the study is the previous founding that any improvement in fuel consumption leads to the remarkable reduction of carbon monoxide emission and improves boiler efficiency. They introduced the air preheater for the air-fuel mixture preheating. They are recommending this method since it has been simulated and validated and finally leads to $\mathrm{h}$ improvement of $4 \%$ to the boiler and reduces the fuel consumption by $4.9 \%$. The research investigates the impact of increasing the inlet temperature of the homogenous mixture which finds to be positive but did show the limit at which it can start to have negative according to the AFR and didn't show how to achieve the best mixtures.

Zhao et al [18] studied the use of the Grey Wolf Optimizer (GWO) algorithm in view to optimize air distribution for the coal-fired utility boiler for improving thermal efficiency while reducing unburned carbon by using Artificial Neutral Network (ANN). GWO 
is employed to find the best value of parameters of the boiler and ANN is used to forecast the boiler combustion process. The background of the work is the high consumption of coal-fired power (75\% of the total national production) [19]. So, it is necessary to reduce emission and unburned carbon while improving efficiency by viable, safe, and reliable systems. The results of the test justified that GWO algorithm is effective and the comparison with Particle Swarm Optimization (PSO) and Generic Algorithm (GA) approaches shows that GWO accurately optimizes the boiler performance since it takes a shorter time to run and the author recommends it for online control. The study didn't look at the changes in coal properties.

Lee et al [20] propose supplementary control of the air-fuel ratio. The reason for the research is the determination and updating of the AFR by offline experiments used in the combustion control which causes the reduction of emission of gases to the environment for thermal power plants. As figure3 shows, small AFR leads to the higher emission of carbon monoxide and the high AFR causes greater emission of Nitrite Oxide $\left(N O_{x}\right)$, so there is a need to maintain the AFR to the optimum value. Procedure proposed so far like the double cross-limiting (DCL) strategy can assist the AFR control but, it cannot align with the transient and dynamic response. In the research, two variables have been manipulated which are the fuel flow demand and airflow demand. Two different cases of thermal power plants which are 600-MW and $1000 \mathrm{MW}$ drum-type fired plant have been studied and the results show less fixed control of the AFR for both plants thereby expect the reduction of environmental emission. Although it is also less stable as one can see in Figure 3.

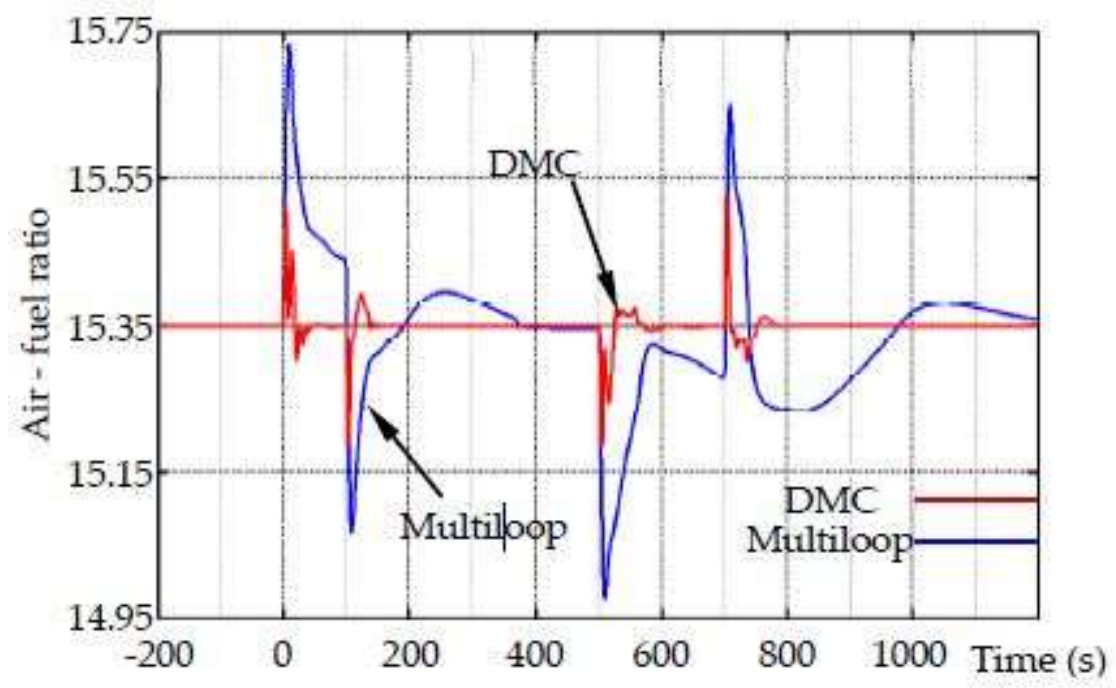

Figure 3: Comparison of Proposed DMC and Existing Multiloops [20].

It is recommended to apply it even for the currently working plants. The research was limited to the control system which requires the setting of the value of references but didn't demonstrate the procedure to follow in setting considering required outputs. Indeed, this control structure requires additional computers because of the number of variables to adjust so it is complicated; the simplified method can be of an advantage.

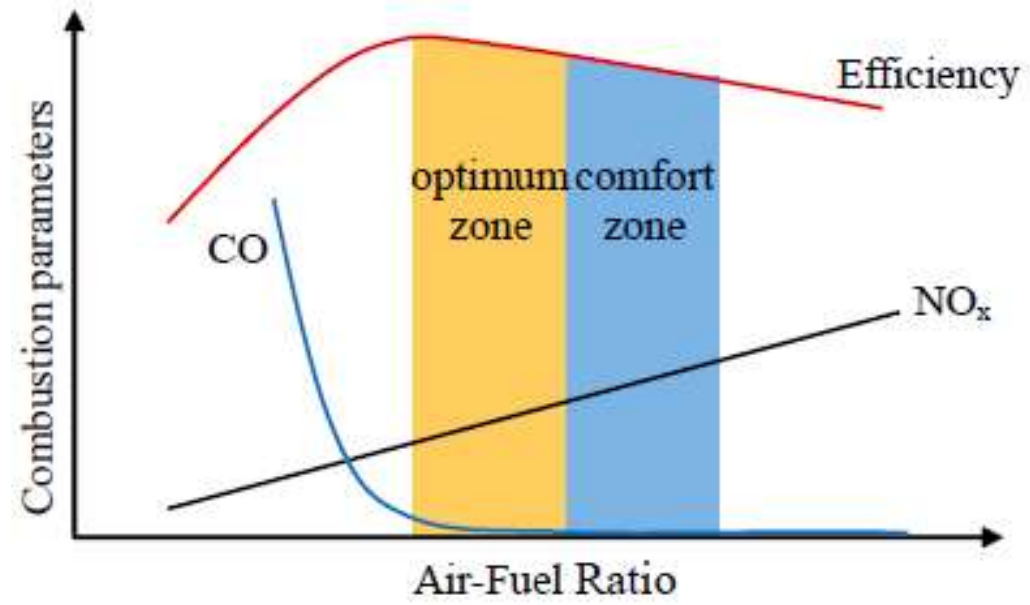

Figure 4: Variation of Environmental emission with AFR [20].

Kuprianov [9] presented the approach of the cost-based optimization of air excess and discussed different applications including firing different types of fossil fuel in industrial boilers. The research found that switching the combustion excess air to optimize its values yields a critical reduction of fuel consumption and environmental impacts. The background of the study is that the 
investigation of the cost was combined with internal and external costs. External cost refers to the environmental impacts whereas internal include the fuel cost. So the author wished to analyze particularly the influences of the excess air to the consumption of the fuel and minimize that. The author recommends the introduction of switches at the level of the air entrance. The author described the role of compromising/optimizing the air in terms the cast did not quantify the air which should enter the furnace taking into account the type and the quantity of the fossil fuel.

There are still a small number of research works done on the oxy-fuel combustion in numerical modeling. This reason motivated Hussein and Naser [21] to study the numerical solution to give an accurate understanding of the chemical and physical mechanism of the oxy-fuel combustion technique. An Eddy BreakUp combustion model with an accurate empirical coefficient has been used in the work. The researcher compared two combustion cases which are air-fried and oxy-fired combustions considering the temperature distributions and species concentrations for the case of $100 \mathrm{~kW}$ down fired furnace. The results showed that the concentration of the flame is in the central for oxy-fuel against the air fired method as in Figure 5. There is also the delay of the combustion for oxy-fired but the concentration of the carbon dioxide is very small in comparison. The author recommends the use of oxy-fuel combustion however it experiences the delay in the combustion process. The research-validated the model with one type of the boiler and didn't study how big that the delay of the combustion can affect the boiler efficiency in general.

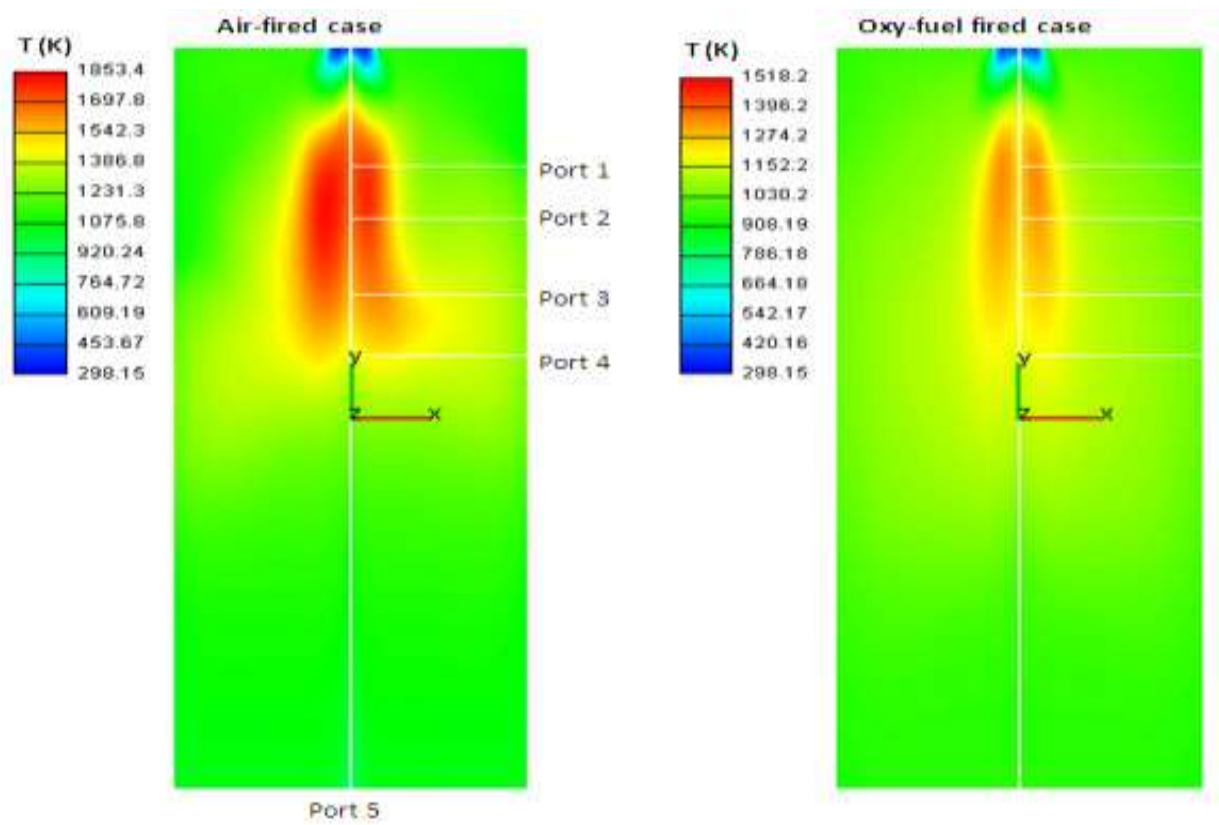

Figure 5: Flame comparison of the Air fired (left) and Oxy fired (right) combustions [21].

Zaporozhets [22] developed the Algorithm of the control system which is based on adjustment of the excess air ratio (EAR). The sensor measures the actual EAR and compares with the value adjusted then gives the command to the fan speed to increase or reduce the frequency as indicated in Figure 4. The background of the work is that most of the control systems of the air-fuel ratio rely on the fixation of $\mathrm{CO}$ and $\mathrm{O}_{2}$ in flue gases. However, the analysis of $\mathrm{CO}$ available in exhaust gases does not provide all information on incomplete combustion. The results indicate the possibility of higher efficient combustion of the fuel considering specific conditions and actual fuel characteristics. It reduces flue gases and minimizes heat losses. Experiments have been conducted on NIISTU-5 boiler and PBGM-type burner only and didn't try different types and they have limited on the setting the EAR which need be explored in terms of calculation based on actual conditions as well as the type of the fuel.

Wall et al [23] researched the application of the oxyfuel coal combustion and compared it with air-fuel combustion. The results show that oxy-fuel has advantages of small emission of $N O_{x}$ and the natural gas consumption rates are lower. This leads to the minimum energy absorption which is advantages in terms of efficiency of the boiler. The other associated advantage is the reduction in the size of the boiler. The authors recommend its practices but didn't investigate the economic case since it requires the installation of some other component including the Air Separation Unit.

Zhou et al [24] presented an approach for forecasting the emission of $N O_{x}$ and carbon burns out of the large pulverized coal-fired boiler. They studied the effect of over-fired air (OFA) flow rate, coal properties, and air distribution. The background of the research is that the field experiments on parameters to achieve optimal values than were not recently done. The experiments have been done on a 600MW tangential coal-fired boiler. The optimal setpoints/values which minimize $N O_{x}$ emissions and the carbon, 
giving high boiler efficiency are found. The minimization of $N O_{x}$ is linked to the reduction of the excess of the air which indicates that the AFR reduced.

According to Wandel et al [25], one of the important thing to consider for efficient combustion is Air Fuel Ratio (AFR), because lower AFR causes the existence of unburned fuel which make unwanted combustion at any place. They discussed the simulation of AFR for Moderate Low oxygen Dilution. The author evaluated AFR based on Unburned Hydrocarbon (UHC). The results show that unburned fuel or UHC will be in the exhaust gas when the oxygen supplied to the combustion chamber is not enough. It indicates that the combustion using a bluff-body burner for the composition of $50 \%$ of methane, $20 \%$ of hydrogen and $30 \%$ of carbon dioxide; for $A F R=4: 1$, gives approximately no UHC in the exhaust gas pipe. The authors recommend the use of a supply of enough oxygen in the combustion chamber. The author didn't study the impact of the excessive air and didn't investigate how this air quantity in need can vary according to the pressure and temperature at the entry.

After the establishment of Doosan Power Systems investigating the control and operation of the utility-scale oxy-fuel for combustion in the power plant, Kuczynski et al [26] needed to adopt the optimized designs and develop appropriate control and dynamic optimization strategies of oxy-fuel. The oxy-fuel process excludes all gases rather than oxygen from the air for combustion purposes. They find that recycling flue gas in the oxy-fuel process raises several controls and operational features than conventional air-fired power plant systems. The authors recommend the use of the air separation unit (ASU) to separate the oxygen from other inert gases. Instead of working on the air-fuel ratio, it is considering the oxygen fuel and the main objective is to have complete combustion.

The methods described by different authors reviewed shown some improvement in terms of air-fuel ratio particularly and the optimum working conditions of the boiler in general. However, there is still much to do, to further optimize the efficiency of the boiler. This can be achieved by keeping the AFR very close to the stoichiometric value, minimize the losses via reduction on gases, and making the system sensitive to the ambient temperature.

Adaptation of some methods from the review which showed positive impacts could be combined while avoiding very sophisticated apparatus. The stoichiometric value will be computed using equation(2)[4], for a specific working fluid/fuel (methane gas for instance), since the literature showed its role, however, computations have not been done.

\section{THE IMPACT OF THE INCREASE OF THE OUTDOOR TEMPERATURE}

Janus et al [27] studied the effects of inlet air temperature fuel composition and humidity on combustion stability. The background of the study is the fact that different researches have shown that environmental conditions can vary the stability of the combustion of the boiler. Furthermore, lean premix (LPM) combustion applications where fuel and air are mixed before, to avoid local high temperatures which are on the base of thermal $N O_{x}$. It makes interesting the investigation of the contribution of ambient temperature on the stability of the system. The results have proven that the change of ambient conditions and fuel composition varies the stability, in the sense that it alters transport times. The authors are recommending stabilizing the working temperature by keeping the mixture air-fuel to an environment where they will not change in temperature. The work is limited to the stability study of the combustion. It has not introduced the mechanism to achieve the constancy of the temperature of the mixture.

Fahad [27] researched the influences of the ambient air temperature on the steam generation from the boiler. The researcher worked on this since previous researches investigated the impacts of ambient conditions on the exergy destruction in the combustion chamber and heat transfer only. It was concluded that the increase of ambient air temperature has a small positive impact on the combustion chamber according to Figure 6. The author recommends preheating the mixture to some temperature. The conclusion has been made based on the experiment of one type of the boiler and didn't show exactly the optimum values of the temperature and excess air percentage. 
International Journal of Advances in Scientific Research and Engineering (ijasre), Vol 6 (9), September -2020

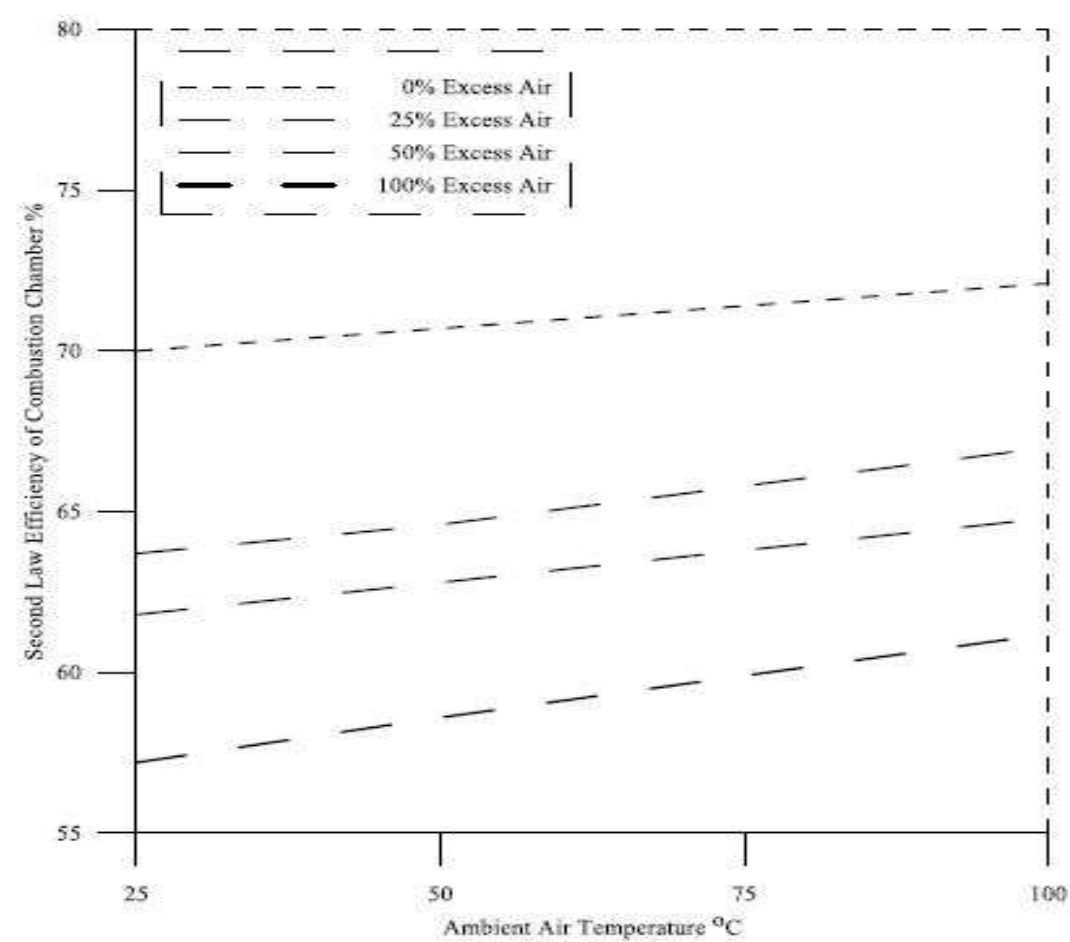

Figure 6: Variation of the Combustion Efficiency with Ambient Temperature [27]

Zhou et al [27] measure the performance of the $300,000 \mathrm{lb} / \mathrm{h}$ steam boiler dependence on ambient air temperature. The research showed a considerable increase in boiler performance with ambient temperature as presented in Figure 7.

This relation is due to the variation of the density with the temperature according to the equation

$$
\eta_{b}=1-\left(L_{d f}+L_{f h}+L_{a m}+L_{r a d}\right)
$$

where $\eta_{b}, L_{d f}, L_{f h}, L_{a m}$ and $L_{r a d}$ is the efficiency of the boiler, loss due to the dry flue, loss due to fuel hydrogen, loss due to air moisture, and loss due to radiation respectively. All these losses are dependent on density, for example

$$
L_{d f}=C_{p} \times A F R\left(\rho_{\text {air }}+\rho_{\text {fuel }}\right) \times\left(T_{g}-T_{a}\right) H H V
$$

, $\rho$ stands for the density. Observing this relation we can remark that if the density becomes small because, on the increase of the temperature, the loss is going to be small. Besides, if the ambient air temperature $\left(T_{a}\right)$ is increasing, the difference $T_{g}-T_{a}$ will decrease and consequently $L_{d f}$ will reduce. $T_{g}$ is the fuel gas temperature, $C_{p}$ is the specific heat of flue gas and $H H V$ is the fuel High Heat Value. The authors recommend that for efficiency maximization, the boiler should be loaded depending on weather conditions and boiler manufacturers should show boiler performance curves corresponding to different ambient temperature values. The authors studied the change of boiler performance with the outside temperature; limited the finding of the variation graph but didn't estimate the rate of change in the model.

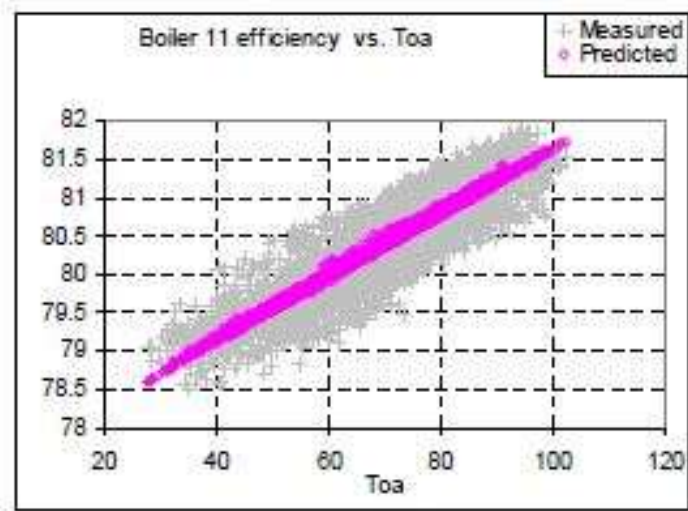

Figure 7: Boiler Efficiency vs Outside Temperature [27]

The relationship of the efficiency of the thermal power plant with climate conditions like temperature variation has previously been found but didn't yet study its implication in different plants. With that reason, Colman [28] quantified this relationship for 
application purposes using regression and Integrated Environment Control Model (IECM) Modeling strategies. The results showed a linear relationship between ambient air temperature and the efficiency of the coal power plant. This relation is quantified as the increase of temperature by $1^{\circ} \mathrm{C}$, leads to the plant efficiency increases increase of $0.02 \%$ in the case other variables are constant. Is research talks about the efficiency of the power plant, in general, didn't specify for the case of the boiler. The author is recommending that the selection of the site to construct the plant should be prioritizing the region with some greater ambient temperature.

Chao et al [29] presented the impact of the inlet air temperature on the thermal efficiency of the boiler system. Computations have been done for different conditions based on the numerical model. The results have proven that when inlet air temperature increases by $12.5^{\circ} \mathrm{C}$, the loss decrease by $0.9 \%$, so; the boiler efficiency increase by the same value of the losses as one can see in Figure 8. The research came up with proof that the increase in the inlet temperature of the air reduces emissions and is positive on the boiler efficiency as in Figure 8. It didn't investigate the optimum value which minimizes all kinds of losses since there are five types of losses as illustrated in [27], and [29]. They recommended the use of stratified combustion technology, with air preheater and thermal insulation measurements to improve boiler efficiency.

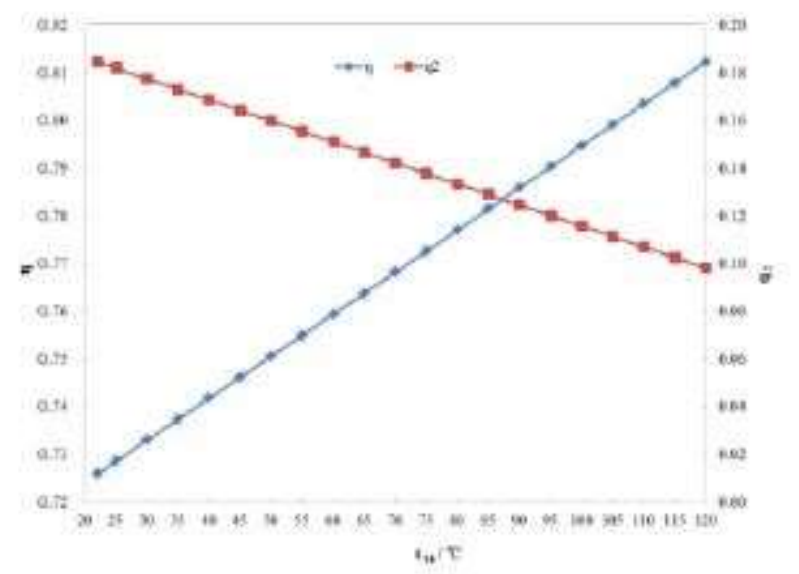

Figure 8: Variation of efficiency (blue) and emission (red) with the ambient temperature [29]

For the case of the dependence of the climatic condition mainly the temperature variation, the literature justifies the reduction of the losses due to the temperature reduction which yields minimum exhausts. The climate experiences the increase of the temperature with years [30], [31]. In some cases where the region has a higher variation in temperature, the settings of the working of the thermal plant can consider this change.

\section{CONCLUSION}

The methods described by different authors reviewed shown some improvement in terms of air-fuel ratio particularly and the optimum working conditions of the boiler in general. However, there is still much to do, to further optimize the efficiency of the boiler. This can be achieved by keeping the AFR very close to the stoichiometric value, minimize the losses via reduction on gases, and making the system sensitive to the ambient temperature.

Different works in the literature showed that the increase of temperature is positive to the boiler efficiency but didn't investigate the limiting value where it starts to be negative; the investigation of that limit would be conducted. The combination of algorithms which are separation of oxygen from the air [23], and control presented in [13] changing it to the way presented in [22], may result in better performance. For the case of the dependence of the climatic condition mainly the temperature variation, the literature justifies the reduction of the losses due to the temperature reduction which yields minimum exhausts. The use of data collected on temperature will be employed to study the case of Rwanda while found the real value of the change on boiler efficiency per increase of one degree Celsius of the temperature, keeping constant other independent variables of the efficiency. This will be useful to find in what can be done on some other variable in the case the temperature is projected to have some change to compensate for the required demand.

Conflicts of Interest: The authors declare no conflict of interest.

\section{REFERENCES}

[1] U.S. Department of Energy, “Guide to Renewable Energy,” Energy Effic. Renew. Energy, p. 2, 2010. 
International Journal of Advances in Scientific Research and Engineering (ijasre), Vol 6 (9), September -2020

[2] P. Sadorsky, "Do urbanization and industrialization affect energy intensity in developing countries?," Energy Econ., vol. 37, pp. 52-59, 2013.

[3] R. T. Vedula, R. Song, T. Stuecken, G. G. Zhu, and H. Schock, "Thermal efficiency of a dual-mode turbulent jet ignition engine under lean and near-stoichiometric operation,” Int. J. Engine Res., vol. 18, no. 10, pp. 1055-1066, 2017.

[4] S. Londerville, J. Colannino, and C. E. Baukal, "Combustion fundamentals," John Zink Hamworthy Combust. Handbook, Second Ed. Vol. 1 - Fundam., pp. 79-124, 2012.

[5] R. P. Tuckett, “THE ROLE OF ATMOSPHERIC GASES,” no. December 2016, 2017.

[6] L. Simona, A. Serban, and S. Paraschiv, "ScienceDirect Calculation of combustion air required for burning solid fuels ( coal / biomass / solid waste ) and analysis of flue gas composition," Energy Reports, no. September, 2019.

[7] Introduction to Modeling and Control of Internal Combustion Engine Systems Springer, 1395.

[8] B. Abbas Al-Himyari, A. Yasin, and H. Gitano, "Review of Air-Fuel Ratio Prediction and Control Methods," Asian J. Appl. Sci., vol. 2, no. 4, pp. 471-478, 2014.

[9] V. I. Kuprianov, "Applications of a cost-based method of excess air optimization for the improvement of thermal efficiency and environmental performance of steam boilers," vol. 9, pp. 474-498, 2005.

[10] C. Hsi and J. K. Ã, "Estimation of fuel burning rate and heating value with highly variable properties for optimum combustion control," vol. 32, pp. 1255-1262, 2008.

[11] S. M. Atnaw, "Modeling and Simulation Study of Downdraft Gasifier Using Oil-Palm Fronds," no. December, pp. 7-8, 2009.

[12] C. Principles, "A Boiler Combustion Control System with Combustion Ratio Optimisation and Soft Measurements," vol. 43, no. May, pp. 112-115, 2010.

[13] 2Yul Y. Nazaruddin and Farida I. Muchtadi 1Handi Santoso M.H., "BOILER PERFORMANCE OPTIMIZATION USING FUZZY LOGIC CONTROLLER,” no. c, 2005.

[14] J. Blondeau, L. Rijmenans, J. Annendijck, A. Heyer, and E. Martensen, "Burner air-fuel ratio monitoring in large pulverised-fuel boilers using advanced sensors : case study of a $660 \mathrm{M} \mathrm{W}$ e coal-fired power plant .,” pp. 1-27.

[15] B. Zhang, Y. Li, and M. Liu, "Case Study: Optimization of an Industrial Steam Boiler System Operation,” no. 2015, 2014.

[16] E. R. Kaiser, “Combustion and Heat Calculations for Incinerator,” Proceedinos 1964 Natioal Inciner. Conf., pp. 81-89, 1964.

[17] U. Ibrahim and S. Farrukh, "Optimization of Fuel in Saturated Steam Boiler through Preheating of Controlled Air-Fuel Mixture,” no. February, 2019.

[18] Y. Zhao et al., "Optimization of Thermal Efficiency and Unburned Carbon in Fly Ash of Coal-Fired Utility Boiler via Grey Wolf Optimizer Algorithm,” IEEE Access, vol. 7, pp. 114414-114425, 2019.

[19] S. Chang, J. Zhuo, S. Meng, S. Qin, and Q. Yao, "Clean Coal Technologies in China: Current Status and Future Perspectives," Engineering, vol. 2, no. 4, pp. 447-459, 2016.

[20] T. Power and K. Y. Lee, "Supplementary Control of Air - Fuel Ratio Using Supplementary Control of Air - Fuel Ratio Using Control for," 2020.

[21] A. H. Al-abbas and J. Naser, "CFD Modelling of Air-Fired and Oxy-Fuel Combustion in a 100 kW Unit Firing Propane ICME11-TH-004 CFD MODELLING OF AIR-FIRED AND OXY-FUEL COMBUSTION IN A 100 KW UNIT FIRING PROPANE," no. August 2017, 2011.

[22] A. Zaporozhets, "Analysis of Control System of Fuel Combustion in Boilers with Oxygen Sensor," vol. 63, no. x, pp. 241-248, 2019. 
[23] T. Wall et al., "Chemical Engineering Research and Design An overview on oxyfuel coal combustion - State of the art research and technology development," vol. 7, no. August 2008, pp. 1003-1016, 2009.

[24] H. Zhou, K. Cen, and J. Fan, "Multi-objective optimization of the coal combustion performance with artificial neural networks and genetic algorithms," no. February, pp. 499-510, 2005.

[25] C. Paper, M. M. Noor, A. P. Wandel, and T. F. Yusaf, "Air fuel ratio study for mixture of biogas and hydrogen on mild combustion," no. May 2014, 2013.

[26] K. J. Kuczynski et al., "Energy Procedia Dynamic Modelling of Oxyfuel Power Plant,” Energy Procedia, vol. 4, pp. 2541-2547, 2011.

[27] H. F. Alajmi, "Effect of Ambient Air Temperature on the Performance of Steam Generator," vol. 8, no. 7, pp. 479-483, 2017.

[28] J. Colman, “The Effect of Ambient Air and Water Temperature on Power Plant Efficiency,” no. April, p. $35,2013$.

[29] L. Chao, L. Ke, W. Yongzhen, M. Zhitong, and G. Yulie, "The Effect Analysis of Thermal Efficiency and Optimal Design for Boiler System,” Energy Procedia, vol. 105, pp. 3045-3050, 2017.

[30] R. Ddamulira, "Climate change and energy in East Africa,” Dev., vol. 59, no. 3-4, pp. 257-262, 2016.

[31] USAID, "Climate Change Adaptation in EAST AFRICA," Clim. Chang. Adapt. EAST AFRICA, 1980. 